\title{
Reducing Incidences of Medication Errors at home through Technology
}

\author{
Priya Prasad ${ }^{1}$, Sanjay P. Wate ${ }^{2}$ \\ ${ }^{1,2}$ (Pharmaceutical Sciences, Sharad Pawar College of Pharmacy/Nagpur University, India)
}

\begin{abstract}
Medicines are found almost in every household of India. Due to the complex use of medicines, there may be many errors, mistakes, doubts and queries related to medicines among outpatients. This is basically a research survey, conducted to ensure the necessity of a toll free medicine helpline number in India, to answer the queries of the general public. Mobile phones are the fastest means of communication and obtaining information instantly. So we can use this technology to get instant information related to medicines. For this study a questionnaire was designed for outpatients. Their answers were statistically analyzed and based on the results, conclusions were drawn.
\end{abstract}

Keyword: Free medical helpline number, healthy citizens, mobile phones, medicines, and medication errors

\section{Introduction}

Administration of medicines in the correct dose and in the correct form and at the correct time is very important. Any mistake or any error while administrating medicines may prove detrimental to health and can sometimes even turn fatal. Medical errors may be defined as "...any preventable event that may cause or lead to inappropriate medication use or patient harm, while the medication is in the control of health care professional, patient, or consumer". ${ }^{[1]}$ Medication errors take place as various levels such as during prescribing; order communication; product labeling; packaging and nomenclature; compounding; dispensing; distribution; administration; education; monitoring; and use. The safe and accurate administration of medications is one of the most important responsibilities of the person who is administering it, even if it is self administered. Drugs are the primary means of therapy for clients with health problems, but a drug may have the potential for causing harmful effects when administered improperly. The categories of the people who have the least knowledge of the medicines are the consumers or the patients. So there are probably more chances of committing medication errors from their side.

\subsection{Common medication errors}

The common medication errors that the consumers make are: Omission: the patient fails to receive the required drug dose. Wrong dose: the patient takes or receives a dose that's at least 5\% more or less than the dose ordered. Extra dose: the patient receives more doses than the doctor ordered. Unordered drug: the patient takes or receives a drug that wasn't ordered for him. Self-medication: the patient takes or receives a drug which may be harmful for him Wrong time: the patient receives a drug too early or too late. In the hospitals the nurse is responsible for understanding a drug's action and it 's side effects, administering it correctly, monitoring the client's response and helping the client self administer drugs correctly and knowledgably. But who will take care of the outpatients? They do not have any nurse to take care of their medication needs. The outpatients are themselves responsible for the correct administration of medicines.

1.2 Rights of drug administration:

There are certain rights to the administration of medicines which should be taken into account. They are:

The right patient

The right drug

The right dose

The right route

The right time

The right to know information about the drug

The right to refuse the drug

The right documentation ${ }^{[2]}$

Despite repeated emphasis on the "Rights of Drug" administration, too many patients receive or take wrong medication. This generally happens due to the lack of knowledge of the medicines, that the patients takes or receives. 
II. Literature review

Leape and colleagues reported in 1995 that medication errors occur at different concentrations depending on the stage of the medication or prescribing process. Most medication errors occur during physician ordering (39\%) and medication administration $(38 \%){ }^{[3]}$

Research shows that in India consumers in general know very little about the drugs they use, their effects and their basic mechanisms. ${ }^{[4]}$

Holloway and Kotwani (BMC infectious diseases, 2011) observed a very high consumption of antibiotics in both public and private sector outpatients. There was a high use of broad spectrum and newer antibiotics in the community. ${ }^{[5]}$

Poor health affects both the ability to save and the impetus to save. Sickness can have a large effect on out-of-pocket medical expenses, which can reduce current and accumulated household savings. This occurs in developed countries but is of particular concern in developing countries. ${ }^{[6]}$

Other studies show that although modern pharmaceuticals are based on a rational-scientific model, in practice, they are distributed, prescribed and used in ways that frequently don't accord with that model. ${ }^{[7],[8]}$

In many developing countries the weakness of public and private insurance systems means that out of pocket spending by households is the main source of financing of the health system. For example, in India $83 \%$ of health spending comes from the private sector and $94 \%$ of the private sector spending is out of pocket expenses (World Health Organization, 2007). ${ }^{[9]}$

Health shocks mean that families may be thrown into poverty if there is a lack of insurance and productive assets such as land or animals must be sold to pay for medical expenses. ${ }^{[10]}$

\section{Method}

A research survey was the method adopted by me because it would help to determine the medication errors which exist in our society.

In this study I have tried to determine the possible reasons for medication errors or mistakes which may be made by the patient himself due to lack of information or lack of knowledge of the medicine, which they consume. I have also tried to ensure the need for patient education, regarding medicines via telecommunication, as it is the fastest means of communication.

\subsection{Sampling}

This cross-sectional study was conducted at 40 different clinics and hospitals of Nagpur, Maharashtra, India between June and August 2012. The target group selected were the patients at different hospitals and clinics who were there to consult the OPD physician. Outpatients were selected for the study as they are the one who consume more medicines as compared to other general public. They are the one who take medicines under self-guidance or family guidance. A total of 500 patients who were aged above 18 years participated in this survey. The percentage of female patients was $66 \%$ and that of male was $34 \%$. The survey was carried out with the permission of the person in charge of the clinics and hospitals. Participation was voluntary and no patients were compelled to participate in the survey.

\subsection{Questionnaire Design}

The survey consisted of 2 parts. Part One asked the respondents about the demographics (e.g., name, age, sex, occupation, and illnesses). Part Two of the survey contained 10 questions; the first question in this part asked that how many times in a month or year they visit a physician? This was to determine as to what extent the patients are dependent on medicines for their illnesses. The second question in this part asked whether or not the doctor explains the patients about the medicines he prescribes. This was to see, how well the patients were informed about the medicines prescribed to them. The third question of this part asked as to from where the patients purchase medicines or did they get complimentary samples from the doctor. The fourth question asked them whether or not the pharmacist in the medicine store explained to them the dos and don'ts of medicines. The third and fourth question was to ensure the person responsible for patient education and whether or not did they carry out their duty. The fifth question of this part asked them whether or not they check the expiry date of the medicines before buying consuming them. This was to get an idea about the percentage of people that might me affected because of the expired drug. The sixth question of this part asked them whether or not did they have doubts related to the medicines that how it should be taken. This was to get an idea of the dose and schedule related errors which the patients generally make. The seventh question of this part asked the patients about the adverse reactions they had. This was asked because adverse reactions are generally due to medication errors. The eighth question of this part asked the patients, the doubts or questions which they generally have while consuming any medicine. This was to get an idea about the possible reasons of medication errors likely to be made by the patient and which can be prevented if they have the proper knowledge. The ninth question of this part asked the patient about whether or not they prefer self- medication. This was asked because self medication may be responsible for harmful administration of wrong medicines. The tenth question 
of this part asked whether or not they think that there should be a National Medicine Helpline Code to educate them and answer their queries related to the use of medicines. This was asked to ensure the need of a National Medicine Centre with toll free helpline number in India.

\subsection{Statistical Analysis}

There were 330 female patients and 170 male patients who participated in the survey (total=500). The patients who were below the age of 18 were not allowed to participate in this survey. A simple bar graph and a pie chart have been used to demonstrate the demographics of the participants.

\subsubsection{Patient's demographics profile}

Fig. 1 shows the number of male and female participants who participated in the survey. There were $330(66 \%)$ female patients and $170(34 \%)$ male patients who participated in the survey. Table 1 shows the number of participants according to their age. The age of the patients were collapsed into 7 categories. The first aged between 11 and 20 years old, second aged between 21 and 30 years old, third aged between 31 and 40 years old, fourth aged between 41-50 years old, fifth aged between 51 and 60 years old, sixth aged between 61 and 70 years old, and seventh aged between 71 and 80 years old.

3.3.2 Classification of patients

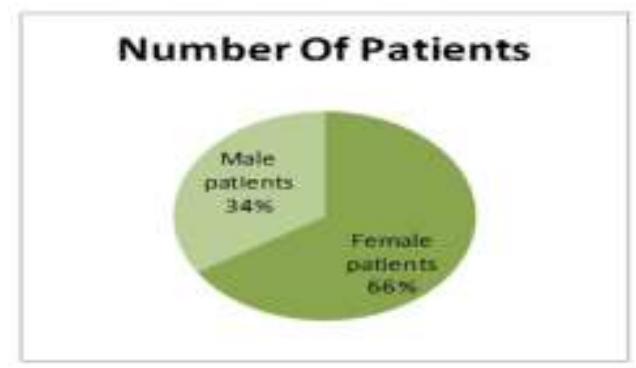

Fig. 1 Number of patients

Table 1 Classification of patients based on age group

\begin{tabular}{ccc}
\hline Sr. No & Age & Number of patients \\
\hline 1. & $11-20$ & 10 \\
2. & $21-30$ & 210 \\
3. & $31-40$ & 160 \\
$\mathbf{4 .}$ & $41-50$ & 30 \\
$\mathbf{5 .}$ & $51-60$ & 30 \\
$\mathbf{6 .}$ & $61-70$ & 50 \\
$\mathbf{7 .}$ & $71-80$ & 10 \\
\hline $\mathbf{8 .}$ & Total & 500 \\
\hline
\end{tabular}

Most of the patients were aged between 21 and 30 years because they were selected purposely as the younger generation are more technology driven and they are the main determinants for the need of a technological revolution.

4.1 Question no. 1 respondents

\section{Results}

Fig. 2 shows the frequency of physician visits annually in different class of patients
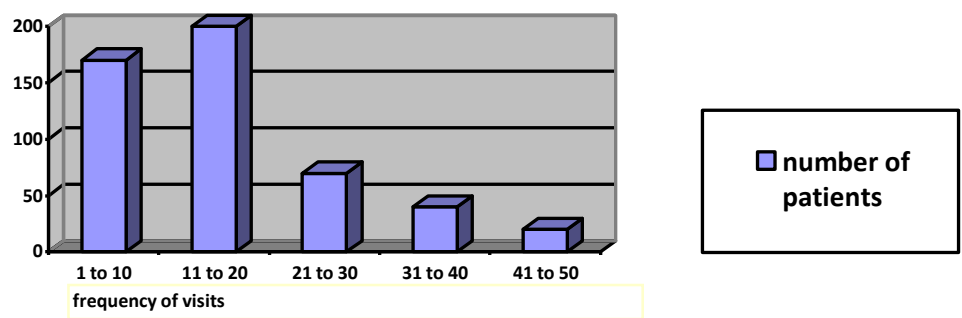

Fig. 2 Frequency of visits to a physician's clinic or hospital

It was seen that nearly 200(40\%) patients visit doctors almost 11 to 20 times in a year while $170(34 \%)$ patients visit doctors for 1 to 10 times in a year. It was also seen that 70(14\%) patients visit doctors nearly 21 to 30 times and $60(12 \%)$ of patients visit doctors 31 to 50 times in a year as they were suffering from chronic 
illnesses like hypertension, hypotension, diabetes and heart disease which require continuous medical intervention.

\subsection{Question No. 2 respondents}

About 250(50\%) patients said that their doctors explained to them the foods to be avoided while on medication. Apart from this the doctor did not explain anything about the medicines. The rest $250(50 \%)$ of the patients said that their doctor did not explain anything about the medicines, they were just handed the prescription.

\subsection{Question No. 3 and 4 respondents}

Almost all the patients said that they bought the medicines from the pharmacy store and none were provided with complimentary samples. Almost all the patients said that the pharmacist in the drug store informed them only about the schedule of the drug. They were not informed about any adverse reactions or side-effects of the medicines. They were not informed whether they should take any precautions or not.

\subsection{Question No. 5 and 6 respondents}

About 310(62\%) patients said that they check the expiry date of the medicines before taking them while 190 (38\%) patients did not think it important and never checked the expiry date of the medicines. About $350(70 \%)$ of the patients said that they have doubts related to medicines as to how it should be taken and this is mainly because; they forget the schedule which was told to them orally as they discarded the portion of the cover on which the schedule was written by the pharmacist after consuming the medicines; and also because they are not able to read the prescription.

\subsection{Question no. 7 respondents}

About 80 (16\%) patients reported that they had had some kind of adverse reactions after taking some medications. About $10 \%$ patients said that those medications which caused the adverse reactions were taken by self and the rest of them said that it was prescribed. The reactions of those medicines were generally allergy, nausea, breathlessness etc.

4.6 Question No. 8 respondents below:

Almost all the patients had some or the other doubts or questions related to medicines which are listed

- Can bitter medicines taken with honey or sugar?

- What kind of foodstuffs are to be avoided when on medicines?

- Sometimes I forget to take medicines, what should I do?

- Will missing a medicine affect me adversely?

- Is there any home remedy before taking any medicine?

- Some medicines do not improve my condition, what should I do?

- Can I take medicines for allergy without showing the doctor?

- Can the same dose be given to children and adults for some medicines?

- If the children at home take the medicine of adults while playing, will that need a doctor?

- I frequently use painkiller, will it affect my health?

- I forget the schedule sometimes.

- What are the side-effects of my medicines?

- When I am prescribed too may medicines I get confused.

- Which painkillers are banned in the market?

- Where and how should I store a particular medicine?

- Why do some medicines react adversely?

- Can I take OTC medicines if I am on other medicines?

- Sometimes my medicine change color. Should I take it?

- Have I been prescribed the right medicines?

- What medicine I have been prescribed?

- Am I taking the right OTC medicine?

- If I miss a pill. Can I take two the next time?

- Can multiple tablets be placed together for a day's regime?

4.7 Question no. 9 and 10 respondents

About 330 (66\%) patients said that they have felt the need for self-medication for some common and general discomforts like allergy, nausea, dysentery, body ache, ulcers, wounds etc. Almost all the patients said that, there is a compelling need for a National Medicine Centre with a Toll Free helpline code as it would really 
benefit them as they have many doubts and queries which go unanswered. They think that lack of knowledge of the medicine which they consume, in some way or the other is affecting their health and this could be prevented if there is someone who can provide them with information.

\section{Discussion}

In this study it was found that patients are more prone to make medication errors at home because of lack of information about the medicines. It was seen that the doctors and pharmacist are too busy to explain to them the dos and don'ts of the medicines that they prescribe. Considering the doubts and queries which the patients have as described under the result section, it may be considered that patient education play a vital role in avoiding medication errors at home.

The general public needs information and education on medicines and appropriate treatment seeking strategies for a number of compelling public health reasons:

$\rightarrow$ Because of the important role of pharmaceuticals in modern health care;

$\rightarrow$ So that individuals and communities can take responsibility for their health, including decisions on appropriate therapeutic strategies: both a human right and prerequisite for sound decision-making;

$\rightarrow$ So that as consumers they have the basic tools for rational and safe direct purchase of medicines, and can put in context the claims of commercial drug promotion: both critical areas in view of the extent of self-medication;

$\rightarrow$ So that as patients they can be informed about the therapeutic decision making and subsequent drug use: an essential element for optimal therapeutic outcomes since the patient is the final determinant of drug use.

While there is a direct effect of health on the economy, there is also an impact of the health system on the economy irrespective of the ways in which the health system affects health. The health sector 'matters' in economic because of its size. As one of the largest service industries, it represents one of the most important sectors. ${ }^{[11]}$ Therefore health sector also influences the country's economy.

\section{Recommendations}

Considering all the factors above, it may be recommended that there a compelling need for a major technological advancement in the health care sector of India. Not only production of medicines, but also its safe and correct use is of utmost importance to improve the health conditions of people in India. The telecommunication sector can be very wisely used to take a step forward in strengthening the Indian health sector. Nowadays mobiles have become the fastest means of communication, so this can be used to get any information instantaneously without even stepping out of our homes or offices. Telecommunication can also be used in the heath care sector to set up a National Medicine Helpline Centre with a toll free number to answer the queries and doubts of the general public related to the use of medicines. It can also be used to educate the patients for the safe use of drugs. Recently it was reported according to Right to Information Act (RTI) that Mumbai in India has 43 fake doctors and there may be many more in whole of India. ${ }^{[12]}$ Thus if such helpline is available in India, it would be easy to identify the wrong medicines given by fake doctors.

6.1 The National Medicine Helpline Centre

- A 3 digit code as that of Police, Fire, and, Ambulance, would make it easier for the general public to memorize it and contact it when need arises.

- It can have different departments for male and female.

- It can be located at different cities or states which are linked to each other for call transfers.

- Skilled pharmacists may be employed, who have good communication skills and knowledge of specific languages.

- Databases of all the drugs with their dose, interaction, uses etc. should be available.

- Financial aid may be demanded from the government for its set up.

\section{Conclusion}

It is seen that the medicine consumers in India have been very ignorant about the medicines which they consume. They have little or no knowledge about the medicines which they consume. This may be because there are very few sources available, where they can get information about the medicines. Good health is not only an asset to self and family but it is also an asset to the country. While it has long been recognised that increased national wealth is associated with improved health, it is only more recently that the contribution of better health to economic growth has been recognized. And this relationship has been well-established in lowincome countries. So it has become very important to discuss health in terms of economic development. A country can develop economically only if its citizens are healthy. Therefore steps such as establishment of National Medicine Helpline Centre will certainly aid to the improvement of health conditions in India. Establishment of this centre will surely reduce the incidences of medication errors made by patient at home and it will make the consumers more responsible towards the safe use of medicines. 


\section{Acknowledgements}

I would like to thank the authorities of the hospitals and clinics for giving me the permission to carry out the Research Survey. My sincere thanks also go to all the volunteers for their cooperation as their participation was of utmost importance. I thank my college authorities for funding me and having faith in me. Lastly, I would like to thank my family, friends, and my guide Mr. S. P. Wate for all the support and motivation which has helped me to move on.

\section{References}

[1] National coordinating council for medication error reporting and prevention. About Medication Errors. [updated Jan 2008; cited 2012 August 22]. Available from: http://www.nccmerp.org/aboutMedErrors.html

[2] Five rights of medication administration. Available from: http://www.nurses-neighborhood.com/5-rights.html (accessed August 22, 2012)

[3] L. Leape, D. Bates, and D. Cullen, Systems analysis of adverse drug events.: ADE Prevention Study Group. Journal of American Medical Association, 274, 1995, 35-43.

[4] V. Dua, C. Kunin, and L. White, The Use of Antimicrobial Drugs in Nagpur, India: a window on medical care in a developing country, Journal of Social Science and Medicines, 38, 1994, 717-24.

[5] A. Kotwani and K. Hokkoway, Trends in antibiotic use among outpatients in New Delhi, India, BMC infectious diseases, 11(1) 2011, 98-9.

[6] J. Smith, Healthy bodies and thick wallets: the dual relation between health and economic status, Journal of Economic Perspectives, 13(2), 1999, 145-66.

[7] S.J. Fabricant and N. Hirschhorn, Unprotected Use: irrationality of pharmaceuticals in the developing world, Health Policy and Planning, 2(3), 1987, 204-213.

[8] H.V. Hogerzeil, Promoting Rational Prescribing: an international perspective, British Journal of Clinical Pharmacology, 39 1995, $1-6$.

[9] World Health Statistics, Geneva WHO, WHO, 2007.

[10] K. Xu, D. Evans, K. Kawabata, R. Zeramdini, J. Klavus,and C. Murray, Household catastrophic health expenditure: multi-country analysis, The Lancet, 362, 2003, 111-13.

[11] Mumbai has only 43 fake doctors: RTI query, United News of India, February 3, 2012.

[12] M. Suhrcke, M. McKee, R. Arce, S. Tsolova, and J. Mortensen, The contribution of health to the economy in the European Union. Health and Consumer Protection Directorate-General Report, 2005, 19-30. 